\title{
Potencial de redução da temperatura de superfície pelo aumento do albedo nas diversas regiões brasileiras
}

\author{
GIORDANO, Dominique E. ${ }^{1}$ \\ KRÜGER, Eduardo² \\ ${ }^{1}$ Universidade Tecnológica Federal do Paraná e Instituto Federal Paraná, Curitiba, Brasil. domi.giordano@gmail.com \\ ${ }^{2}$ Universidade Tecnológica Federal do Paraná, Curitiba, Brasil. ekruger@utfpr.edu.br
}

\section{Resumo}

Com o crescimento urbano, as superfícies vegetais são progressivamente substituídas por materiais construtivos que absorvem mais radiação solar e retém o calor, alterando o microclima das cidades, contribuindo para a intensificação da ilha de calor urbano e causando desconforto térmico em regiões mais quentes e nos períodos de verão, além de um maior consumo de energia para refrigeração das edificações. Uma estratégia para reduzir a temperatura de superfície é a utilização de materiais de superfície com maior albedo. Sendo a temperatura de superfície resultado tanto da energia incidente como do albedo, o objetivo deste trabalho foi o de mapear a Irradiância Global Horizontal (IGH) média nas diversas regiões brasileiras de maneira a poder correlacioná-la com o potencial de redução da temperatura superficial que se pode atingir com o incremento do albedo, servindo de orientação para a decisão de onde o uso de um maior albedo pode ser efetivamente útil e quanto de meIhora isso pode resultar. A metodologia do trabalho consistiu em calcular a IGH Média a partir da base de dados compilada pelo Prof. Maurício Roriz, a partir de dados horários, registrados em 411 estações climatológicas do INMET entre os anos de 2000 e 2010 . O potencial de redução de temperatura foi estimado a partir de equação empírica apresentada na literatura da área. O resultado do trabalho foi convertido em mapa temático, utilizando-se do método de krigagem para interpolação dos dados amostrais. Percebe-se a partir dele uma grande variação no potencial de redução da temperatura superficial, tanto entre regiões distintas, quanto para uma mesma latitude.

Palavras-Chave: albedo, microclima urbano, ilhas de calor urbano, conforto térmico, eficiência energética.

\begin{abstract}
Urban growth progressively replaces green areas by building materials, which absorb more solar radiation and retain heat, altering urban microclimate and increasing urban heat island effect and therefore causing discomfort in hotter regions and during summer, with increase energy consumption for HVAC systems. A strategy for reducing surface temperature is to adopt surface materials with higher albedo. Once surface temperature results of both incident energy and albedo, the objective here was generate a Global Horizontal Irradiation (GHR) Map of the Brazilian territory in order to estimate the potential cooling effect of increasing albedo in several regions, serving as guide to decide where albedo increase would be useful, and how much would be its cooling effect. The methodology adopted was to calculate the average GHR using the database created by Prof.MaurícioRoriz, with hourly data of 411 cities from INMET weather stations, between 2000 and 2010. The cooling potential effect was calculated from an empirical relationship presented in the area literature. The results were converted into a thematic map, using the kriging method for interpolating the data sample. In the generated maps larger variations can be noticed in the cooling potential from region to region, noticeable even for same latitudes.
\end{abstract}

Keywords: albedo, urban microclimate, urban heat island, thermal comfort, energy efficiency. 


\section{Introdução}

O fenômeno de llha de Calor Urbano (ICU) consiste na significativa elevação da temperatura de áreas urbanas em relação às de seu entorno, tradicionalmente áreas rurais. Dentre suas consequências estão: desconforto térmico em regiões quentes ou com verões quentes, e consequentemente um maior consumo de energia para condicionamento dos ambientes; favorecimento de inversões térmicas, de onde pode resultar piora na qualidade de ar; e alterações do equilíbrio ambiental local, como aumento da temperatura das águas pluviais que chegam aos corpos d'água (GARTLAND, 2010).

Embora os efeitos das ICU sejam mais intensos em grandes metrópoles, esses podem ser sentidos também em cidades de porte médio, como mostram Amorim et al. (2009) em um estudo comparativo entre as cidades de Presidente Prudente (SP-Brasil) e Rennes (França), encontrando diferenças de temperatura entre as áreas urbana e rural da ordem de $4^{\circ} \mathrm{C}$. Na Região Metropolitana de Curitiba (RMC), Lemos (2011) identificou, em 2006, através de termografia de superfície, uma ICU de aproximadamente 469,56 $\mathrm{km}^{2}$ de área de alcance, ou seja, $62,5 \%$ do aglomerado urbano da RMC; com intensidade de até $6^{\circ} \mathrm{C}$ entre as zonas de alta e baixa temperatura.

A maior parte do território brasileiro encontra-se em áreas de clima quente, onde a mitigação da ICU é obviamente econômica, por reduzir a necessidade de energia para condicionamento de ambientes. Porém, na região sul do paíso inverno é mais rigoroso, de maneira que o interesse energético de redução da ICU depende do ponto de equilíbrio onde a economia com refrigeração no verão não ultrapasse o possível maior gasto com calefação no inverno, ou, ainda, no caso do conforto térmico urbano em espaços abertos, que o período de desconforto nas situações de inverno e verão tenha a menor duração possível.

Um estudo de mitigação de ICU para cinco cidades norte-americanas, feito por Konopacki e Akbari (2002), utilizando simulações dos efeitos diretos e combinados indiretos do aumento de arborização sombreando os edifícios, e do uso de materiais de alto albedo nas superfícies urbanas (coberturas, pavimentos e fachadas), considerou a economia energética com refrigeração no verão e o maior consumo de energia para calefação no inverno resultantes da adoção de tais estratégias de redução da ICU. Tais autores estimaram 1,8GW de redução no consumo elétrico no horário de pico das cidades estudadas, e economia de US\$30milhões para as cidades de Chicago e Sacramento (KONOPACKI e AKBARI,
2002, p.3, 10-12). A latitude de três das cinco cidades do referido estudo (Chicago $42^{\circ} \mathrm{N}$; Salt Lake City $40,8^{\circ} \mathrm{N}$ e Sacramento $38,6^{\circ} \mathrm{N}$ ) são mais altas que o ponto mais meridional do território brasileiro $\left(33,75^{\circ} \mathrm{S}\right)$ e as temperaturas médias anuais nesses locais são semelhantes ou inferiores às da região subtropical brasileira. Esse estudo coloca em aberto a possibilidade de que mesmo no sul e sudeste brasileiros o custo-benefício possa ser vantajoso ao se adotarem medidas de redução da ICU, mas não se pode afirmar, já que os materiais construtivos, o uso de calefação e resfriamento, e a zona de conforto do Brasil sãobastante diferentes das cidades abordadas por Konopacki e Akbari (2002).

Para além da questão energética discutida, é necessário lembrar que as ICU têm diversos efeitos ambientais negativos, como inversões térmicas que dificultam a dispersão de poluentes, maior formação de ozônio devido às temperaturas mais altas e aquecimento e poluição das águas dos rios ao receberem o escoamento das águas pluviais urbanas, alterando o ecossistema.

Muitas são as causas da ICU, como a densidade populacional; distância, forma e orientação das edificações; materiais construtivos; calor gerado por máquinas e equipamentos; quantidade de áreas verdes e arborização da cidade; morfologia e localização geográfica da região. Mas dentre as diversas causas, um papel importante pode ser atribuído à substituição da cobertura vegetal por materiais construtivos, que absorvem grande parte da energia solar convertendo-a em calor. As elevadas temperaturas de superfície dos materiais construtivos típicos, quando expostos à radiação solar, elevam a temperatura do ar, gerando desconforto térmico e maior consumo de energia. Além disso, os materiais construtivos têm uma maior capacidade de reter o calor, armazenando- o em seuinterior, de maneira que continuam a aquecer a atmosfera mesmo após o pôr do sol. Tal fato pode facilitar a ocorrência de inversões térmicas, que por sua vez, impedem a dispersão dos poluentes, resultando frequentemente em uma piora da qualidade do ar.

Se, por um lado, não podemos prescindir da existência das cidades, por outro a crescente conscientização da necessidade de redução do consumo de energia, tanto do ponto de visto econômico como ambiental, associada a uma demanda maior por conforto ambiental, tem levado ao estudo e desenvolvimento de alternativas que amenizem esses impactos ambientais negativos. Neste sentido, a adoção de materiais ditos "frescos", ou seja, de elevado albedo, tem sido largamente defendida como medida passiva para meIhoria do conforto térmico e redução do consumo 
de energia de refrigeração dos edifícios. Segundo Douloset al. (2004), "um balanço térmico melhor pode ser atingido reduzindo-se o ganho térmico no meio urbano e em particular, pela redução da radiação solar absorvida. O papel dos materiais nos edifícios é decisivo para a redução dos ganhos térmicos e sobreaquecimento. $\mathrm{O}$ desempenho térmico dos materiais construtivos é determinado principalmente por suas características óticas e térmicas; o albedo e a emissividade são os fatores mais significativos. O uso de materiais apropriados, os chamados materiais "frescos", podem melhorar o conforto térmico durante o verão."

O albedo é um índice da capacidade que o material tem de refletir parte da radiação solar incidente, variando de 0 a 1. Quanto maior o albedo, maior a porcentagem da radiação incidente que é refletida, e por tanto, uma menor parcela de energia é convertida em calor, resultando em temperaturas superficiais menores. Ainda, a retenção maior ou menor desse calor no interior do material dependerá da emissividade da superfície.

Se o uso de materiais de alto albedo pode ajudar a reduzir a temperatura das superfícies urbanas expostas ao sol, pode por outro lado ser prejudicial. Ao nível do pedestre, pode causar ofuscamento e desconforto visual. Nos edifícios ao redor, como mostra o estudo deSailoret al. (2012) pode causar a piora do conforto térmico, pois a maior parcela de energia solar refletida nas superfícies externas de alto albedo, penetra através dos vidros das janelas, transparentes à luz mas não tanto em relação ao calor (relação radiação de onda curta versus radiação de onda longa).

\section{Objetivo}

O objetivo deste artigo é estimar o potencial de arrefecimento da temperatura superficial resultante de um determinado incremento no albedo de materiais de superfície, de maneira a facilitar uma primeira avaliação da ordem de grandeza do efeito decorrente, e mapear esse potencial sobre as diversas regiões brasileiras. Os resultados podem servir de orientação a respeito de em quais regiões essa estratégia pode ser mais ou menos efetiva, colaborando para uma estimativa preliminar do impacto da adoção de materiais urbanos com alto albedo de superfície.

\section{Método}

Para avaliar a capacidade de resfriamento da superfície que um aumento do albedo teria, foi necessário primeiro identificar a intensidade da energia disponível para ser refletida ou convertida em calor, nas diversas regiões brasileiras.

Assim, a primeira etapa do trabalho foi encontrar dados da Irradiância Global Horizontal (IGH) de diversas regiões brasileiras, e a partir deles, calcular um valor médio significativo do IGH. Em seguida, a partir da IGH, o potencial de resfriamento foi estimado para cada região, nas situações de inverno e verão.

Naterceira etapa interpolaram-se os resultados localizados espacialmente, de maneira a inferir os valores não amostrados, permitindo a geração de um mapa temático que mostrasse a distribuição espacial do potencial de resfriamento do incremento do albedo no território brasileiro.

\subsection{Cálculo da Irradiância Global Horizontal Média (IGH-M)}

A Irradiância Global Horizontal é a medida da quantidade de radiação solar direta e difusa, em Watts, que atinge uma determinada área de $1 \mathrm{~m}^{2}$ de superfície horizontal em um intervalo de tempo de 1hora. Como a quantidade de energia refletida é maior quando o ângulo de incidência se afasta da normal, a máxima energia medida sobre o plano horizontal ocorre ao meio dia, em condições de céu claro.

Por ser um valor muito variável tanto durante o dia como em diferentes épocas do ano, devido à variação do ângulo de incidência durante os movimentos de rotação e translação da terra, sua média é bastante afetada pela seleção dos períodos de análise. Há que se considerar ainda a influência da nebulosidade.

Para se obter um mapa da IGH para o Brasil com uma resolução adequada, é necessária uma grande quantidade de pontos amostrais. $O$ INMET, Instituto Nacional de Meteorologia disponibiliza online séries históricas de 291 estações meteorológicas convencionais, com dados a partir de 1961. Porém, trata-se de dados diários, o que resultaria na média diária da $I G H$, que não seria significativa para este trabalho, uma vez que a IGH durante toda a noite é nula, com valores baixos no início da manhã e no final da tarde, o que reduziria drasticamente a média, tornando-a muito inferior aos valores de pico do meio dia.

Foi adotada então a base de dados compilada e tratada pelo Prof. Maurício Roriz a partir de dados horários do INMET, de 2000 a 2010 (RORIZ, 2012a). Segundo Roriz, "Estes arquivos originais[do INMET](...) apresentavam inúmeras lacunas (...), além de alguns valores obviamente 
GIORDANO, D. E.; KRÜGER, E. Potencial de redução da temperatura de superfície pelo aumento do albedo nas diversas regiões brasileiras. Paranoá, Brasília, n¹1, p. 13-22, 2014.

errados. Assim, a primeira etapa do trabalho consistiu na substituição dos valores absurdos e no preenchimento das lacunas. Nesse sentido, foram aplicados procedimentos consagrados de Controle de Qualidade de Dados Climáticos (PITTIGLIANI, 2000)" (RORIZ,2012b, p.1-2).O tratamento dos dados feito por Roriz evita que haja distorção da média da IGH, tornando essa basemais consistente para a finalidade deste trabalho. Além disso, é uma base ampla, apresentando dados de 411 cidades brasileiras.

Devido à sua variabilidade, considerou-se que o ideal para gerar os cálculos deste trabalho não seria adotar um horário e dia do ano fixos para a tomada da IGH, mas sim calcular sua média sobre um período longo o suficiente para diluir valores incomuns ou extremos, incluir a influência de nebulosidade típica, mas curto o suficiente para ser representativo de um período específico do dia e do ano. Para corresponder com as maiores temperaturas superficiais que causam maior desconforto, foi tomado como ponto central o horário do meio dia, do solstício de verão. Para estender o cálculo da média em torno deste ponto central, foram tomados os valores medidos entre $11 \mathrm{~h}$ e 13h, no período compreendido entre 20 dias antes e 20 dias depois do solstício de verão, ou seja, de 01 de dezembro a 10 de janeiro. Sobre os dados medidos neste período, foi calculada a média simples da IGH, arredondada para o valor inteiro mais próximo, obtendo-se assim a IGH Média de Verão (IGH-MV) de cada uma das 411 cidades.

Para uma maior confiança e agilidade na separação dos dados, os dados originais de cada cidade, no formato EPW, foram importados para uma planilha eletrônica, e a seleção e cálculo da média foram realizados utilizando-se macros e filtros de dados. Uma vez calculada, a IGH-MV de uma cidade era transferida manualmente para um único arquivo, juntamente com sua posição e identificação. dias antes e depois do solstício de inverno, ou seja, de 01 de junho a 11 de julho.

O resultado foi uma tabela resumo das 411 cidades, como a mostrada apenas parcialmente (Tabela 1), devido à sua extensão. A localização espacial das cidades amostradas aparece na Figura 1

Figura 1: Pontos Amostrais: localização das cidades brasileiras cujos dados climáticos serviram de base para os mapas temáticos.

\subsection{Estimativa do Potencial de Arrefecimento da Temperatura de Superfície (PATS)}

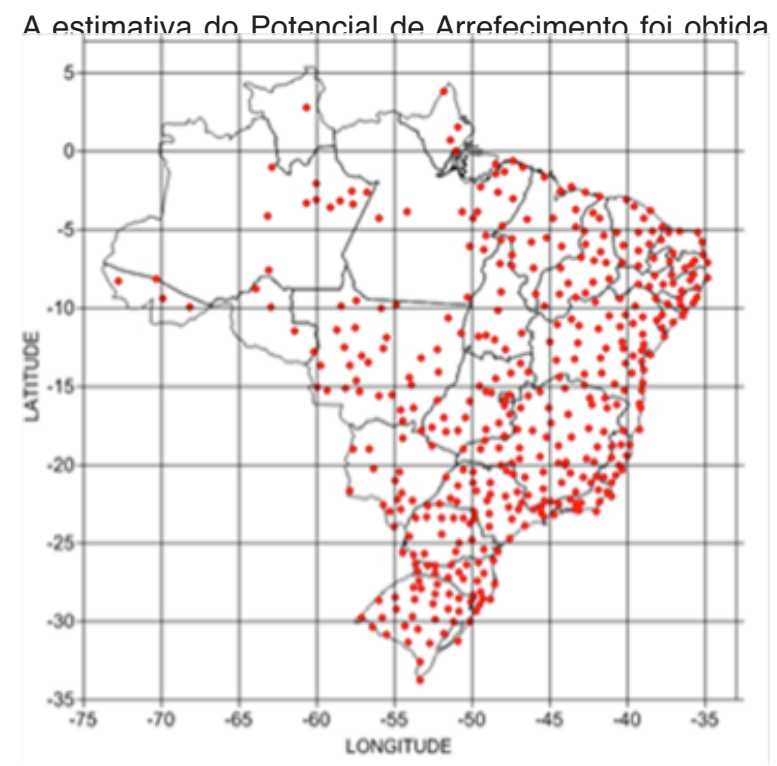

através de correlação empírica de comportamento linear apresentada por Li, Harvey e Kendall (2013), a partir de trabalho conduzido no Centro de Pesquisas em Pavimentos da Universidade da Califórnia. Em seu trabalho, Li, Harvey e Kendall (2013) analisaram 9 diferentes tipos de pavimentos, sendo 3 tipos de asfalto, 3 de concreto e 3 de blocos inter-travados (paver), em

Tabela 1: Resumo da Irradiância e Potencial de Arrefecimento da Temperatura de Superfície por Cidade.

\begin{tabular}{|l|l|c|c|c|c|c|c|c|}
\hline \multicolumn{2}{|c|}{ Local } & \multicolumn{3}{c|}{ Posição } & \multicolumn{3}{c|}{ Verão } & \multicolumn{2}{c|}{ Inverno } \\
\hline UF & \multicolumn{1}{|c|}{ Município } & Lat. & Long & Alt. & $\begin{array}{c}\text { IGH-MV } \\
\left(\mathbf{W h} / \mathbf{m}^{\mathbf{2}}\right)\end{array}$ & $\begin{array}{c}\text { PATS-V } \\
\left({ }^{\circ} \mathbf{C} / \mathbf{0 . 1} \mathbf{a l b} .\right)\end{array}$ & $\begin{array}{c}\text { IGH-MI } \\
\left(\mathbf{W h} / \mathbf{m}^{\mathbf{2}}\right)\end{array}$ & $\begin{array}{c}\text { PATS-I } \\
\left({ }^{\circ} \mathbf{C} / \mathbf{0 . 1} \text { alb. }\right)\end{array}$ \\
\hline AC & Feijó & $-8,14$ & $-70,34$ & 163 & 627 & 3,8 & 568 & 3,4 \\
\hline AC & Pq. Estadual Chandless & $-9,37$ & $-69,93$ & 206 & 538 & 3,2 & 549 & 3,3 \\
\hline AC & Porto Walter & $-8,27$ & $-72,74$ & 240 & 629 & 3,8 & 658 & 3,9 \\
\hline
\end{tabular}

Para fins de comparação, foi calculada também a Irradiância Global Horizontal Média de Inverno (IGH-MI), seguindo-se os mesmos critérios: dados medidos entre $11 \mathrm{~h}$ e $13 \mathrm{~h}$, no período entre 20 amostras de $4 \mathrm{~m} \times 4 \mathrm{~m}$ de área superficial. Para cada material, uma amostra era permeável e as outras duas impermeáveis.

Destas amostras de pavimento, foram medidos o 
albedo e a temperatura do pavimento; irradiância global incidente, além das condições climáticas presentes durante as medições (temperatura do ar, velocidade do vento, umidade relativa, pluviosidade e radiação solar). As medidas de temperatura foram feitas com termopar, e as de albedo e irradiância, usando um piranômetro duplo, ou seja, sobre um tripé, um sensor voltado para baixo captava o albedo da superfície ao mesmo tempo em que um sensor voltado para cima captava a irradiância global, reduzindo o erro de medição. As medições foram feitas em quatro diferentes épocas durante um ano, e em cinco diferentes pontos de cada amostra, próximas ao meio dia, horário de pico da irradiância. Parte das medições foi feita de forma descontínua no tempo, sendo que uma das amostras foi monitorada continuamente ao longo de um ano inteiro.

Dentre os resultados e conclusões de Li, Harvey e Kendall (2013), os mais relevantes para o âmbito deste trabalho relacionam-se à variação do valor do albedo em relação às diferentes condições de radiação solar, apresentados a seguir:

a. Variação diária do albedo: $O$ valor do albedo varia durante o dia, em função da variação do ângulo de incidência da radiação solar, sendo este valor mais alto e variável pelo início da manhã e fim de tarde, e mais baixo e relativamente constante entre $9 \mathrm{~h}$ e $15 \mathrm{~h}$.

b. Variação anual do albedo: Para o estudo dos autores citados, não houve variação significativa ao longo do ano, à exceção de um leve aumento no inverno devido à maior inclinação do sol. A latitude aproximada da cidade onde se localiza o Centro de Pesquisa onde os autores declaram ter realizado os ensaios é de $38^{\circ} \mathrm{N}$, o que implica em ângulos de incidência maiores no inverno do que os que ocorrem sobre o território brasileiro, sendo assim válido assumirmos a constância do albedo ao longo do ano para todo o território, para a finalidade deste trabalho.

c. Influência da nebulosidade: O valor do albedo é reduzido sob condições de forte nebulosidade. Para o presente estudo, o efeito da nebulosidade foi considerado ao se optar pela não exclusão dos dados de irradiância em dias nublados do período utilizado para o cálculo da Iradiância Global Horizontal Média.

Finalmente, para identificar a influência do albedo sobre a temperatura de superfície dos pavimentos, $\mathrm{Li}$, Harvey e Kendall (2013), realizaram de maneira contínua a medição de temperatura nas 9 amostras de pavimento de um outono ao verão do ano seguinte. Correlacionando as temperaturas máximas e mínimas de verão e inverno com os diferentes albedos, observaram um comportamento linear de resposta, mas com coeficientes angulares diferentes para as duas estações, concluindo que o albedo tem grande influência na temperatura tanto no verão como no inverno, mas com intensidades distintas para as duas épocas do ano.

A partir das diferenças de temperatura medidas entre pavimentos de diferentes albedos, os autores daquele trabalho calcularam o "Efeito de Arrefecimento" de se aumentar o albedo em um incremento de 0,1 (EAalbedo). Correlacionando esse Efeito de Arrefecimento do albedo com a Radiação Solar de Pico (q) do mesmo dia encontraram uma relação aproximadamente linear, conforme mostra a Equação 1.

$\mathrm{EA}_{\text {albedo }}=6 \mathrm{q}$

Onde:

EA $_{\text {albedo }}$ é o efeito de arrefecimento da temperatura de superfície do pavimento resultante de um aumento de 0,1 no valor do albedo;

q é o pico de fluxo de radiação global solar atingindo a superfície do pavimento, em $\mathrm{kW} / \mathrm{m}^{2}$.

\subsubsection{Cálculo do Potencial de Arrefecimento da Temperatura de Superfície (PATS)}

A Equação 1do Efeito de Arrefecimento desenvolvida por Li, Harvey e Kendall (2013), foi adaptada para este estudo, substituindo-se a Radiação Solar Global de Pico (q) em kW/m² pela Irradiância Global Horizontal Média de cada cidade (IGH-M), em $\mathrm{Wh} / \mathrm{m}^{2}$, calculada em torno do horário de pico, e por um período de 41 dias, em torno do solstício de verão ou de inverno, conforme explicitado previamente no item 3.1. O Efeito de Arrefecimento (EAalbedo) transforma-se então na estimativa do Potencial de Arrefecimento da Temperatura de Superfície (PATS) adotado neste trabalho como dado base para geração dos mapas temáticos. A equação adaptada adotada para este trabalho é a Equação 2.

PATS $=6^{*}(\mathrm{IGH}-\mathrm{M}) / 1000$

Onde:

PATS é o Potencial de Arrefecimento da Temperatura de Superfície, estimado para a localidade e estação do ano considerados, em ${ }^{\circ} \mathrm{C} / 0,1$ incremento de albedo $\left({ }^{\circ} \mathrm{C} / 0,1 \mathrm{alb}\right)$;

IGH-M é a Irradiância Solar Global Média, em $\mathrm{Wh} / \mathrm{m}^{2}$, calculada a partir das leituras realizadas entre $11 \mathrm{~h}$ e 13h, por 41 dias em torno do solstício da estação do ano considerada, para uma determinada localidade.

Uma limitação da adaptação da Equação 1para este trabalho é que ela foi originada a partir de um estudo 
de pavimentos de apenas 9 tipos diferentes, com apenas 3 tipos de materiais (concreto, asfalto e paver). Outra limitação, é que ao adotá-la, estamos considerando o efeito somente sobre superfícies horizontais.

Ainda assim, como estimativa de referência da variação espacial desse efeito sobre as diversas regiões brasileiras pode ser útil e válida até que estudos mais aprofundados possam ser conduzidos. Os dados calculados para cada localidade tanto de IGH-M, como de PATS para verão e inverno foram então tabelados conforme ilustra aTabela 1.

\subsection{Geração dos Mapas Temáticos}

Os dados calculados para as 411 cidades e reunidos na Tabela 1, serviram então de dados amostrais para inferir os valores não amostrados no espaço entre esses pontos. O método de interpolação dos dados utilizado foi o método da krigagem. Tanto para a interpolação de dados como para a geração dos mapas foi utilizado o software Surfer9.

\section{Análise de resultados}

\subsection{Avaliação da distribuição espacial da Irradiância Global Horizontal Média (IGH-M)}

O maior desconforto térmico causado pelas altas temperaturas das superfícies urbanas ocorre sem dúvida durante o verão. A distribuição espacial da IGH-MV sobre o território, calculada para

Figura 2: Mapas delrradiânciaGlobal Horizontal Média (IGH-M): (A) solstício de verão; (B) solstício de inverno

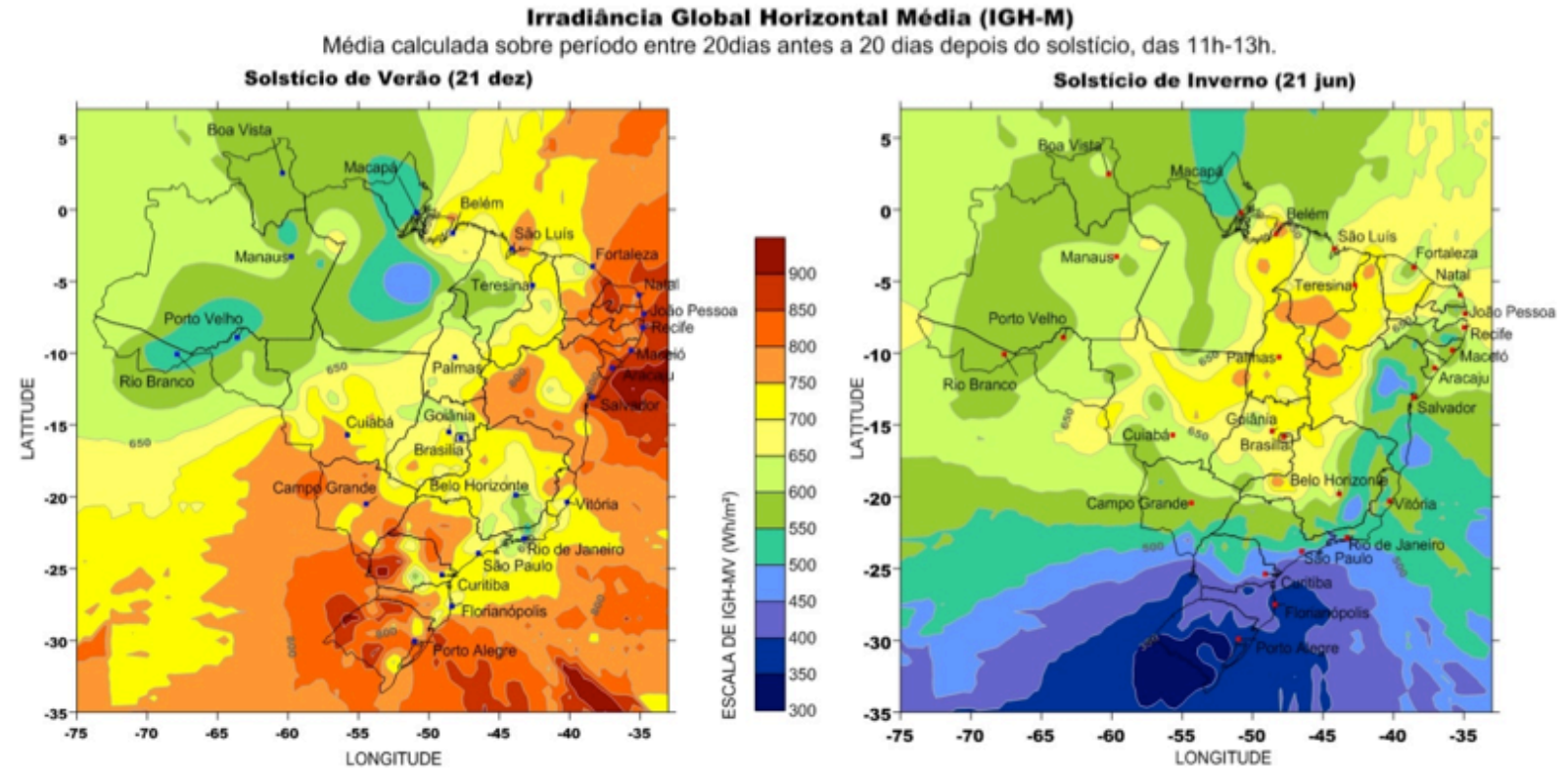

o período de verão, está apresentada no mapa temático da Figura 2A, e a distribuição da IGH-MI para o período de inverno, na Figura 2B.

Pode-se observar nestes mapas como a irradiação é distinta em intensidade para os diversos pontos do território nacional, mas também como há grandes variações até para uma mesma latitude.

A região Norte, por exemplo, com clima Equatorial, apresenta no período considerado de verão, IGH-MV consideravelmente mais baixas que a Região Nordeste na mesma latitude. Apresenta ainda irradiâncias mais baixas no período definido como verão do que no período definido como inverno.
Na região Sul do país, as irradiâncias são altas no período de verão e baixas no período de inverno, como era de se esperar, e as grandes amplitudes térmicas (variações sazonais na temperatura média do ar) da região são corroboradas pela grande amplitude na irradiância entre inverno e verão. Na situação de inverno, abaixo do Trópico de Capricórnio $\left(23,5^{\circ} \mathrm{S}\right)$ as irradiâncias apresentam-se mais graduais segundo a latitude, porém acima dele, nota-se uma distribuição irregular por grau de latitude.

Para a região Nordeste, as irradiâncias que se apresentam mais altas na faixa leste, durante o verão, no inverno se invertem, tornando-se mais intensas no interior, a oeste. 
4.2. Avaliação da variação do Potencial de Arrefecimento da Temperatura de Superfície

Os mapas do Potencial de Arrefecimento (Figura 3), como esperado dada a relação linear estabelecida, seguem o mesmo padrão de distribuição das Irradiâncias Médias, apresentando grandes variações entre regiões e para uma mesma latitude. $\mathrm{Na}$ latitude $5^{\circ} \mathrm{S}$, para a situação de verão por exemplo (Figura 3A), a substituição de um material por outro com valor de albedo $10 \%$ mais alto resultaria em uma temperatura em torno de $2,5^{\circ} \mathrm{C}$ mais baixa sobre o centro do Pará, enquanto no interior do Rio Grande do Norte resultaria em uma temperatura de superfície $5,0^{\circ} \mathrm{C}$ mais baixa, ou seja, a estratégia de aumentar o albedo seria duas vezes mais efetiva no Rio Grande do Norte nessa comparação. Ainda para a situação de verão, ao longo da faixa leste, notamos variações significativas, de $3^{\circ} \mathrm{C}$ próximo a Belo Horizonte a $5^{\circ} \mathrm{C}$ no Rio Grande do Norte e Rio Grande do Sul.
O Potencial de Arrefecimento é consideravelmente mais intenso durante o verão (Figura 3A), com irradiâncias mais elevadas do que durante o inverno (Figura 3B), quando tal potencial diminui. Isso de certa forma dá ao albedo uma característica "seletiva", ou seja, apresentando um efeito maior de resfriamento quando é mais necessário (verão) e reduzindo seu efeito quando ele é menos desejado (inverno). Este efeito pode ser bastante útil se explorado adequadamente em altas latitudes, onde é preciso tratar do conforto térmico para situações muito distintas entre os períodos de inverno e verão.

De forma geral, nota-se que para a região tropical analisada, os potenciais de arrefecimento giram em torno de 3 a $5^{\circ} \mathrm{C} / 0,1$ albedo, apontando para o grande potencial que a adoção de materiais com altos albedos pode ter para o conforto térmico urbano (em condições próximas às superfícies insoladas urbanas -efeito ao nível do pedestre).

Entretanto, deve-se alertar para o fato de que tal efeito, enquanto possa promover a melhoria do grau de conforto ao nível do pedestre em termos

Figura 3: Mapas do Potencial de Arrefecimento da Temperatura de Superfície (PATS): (A) solstício de verão; (B) solstício de inverno.

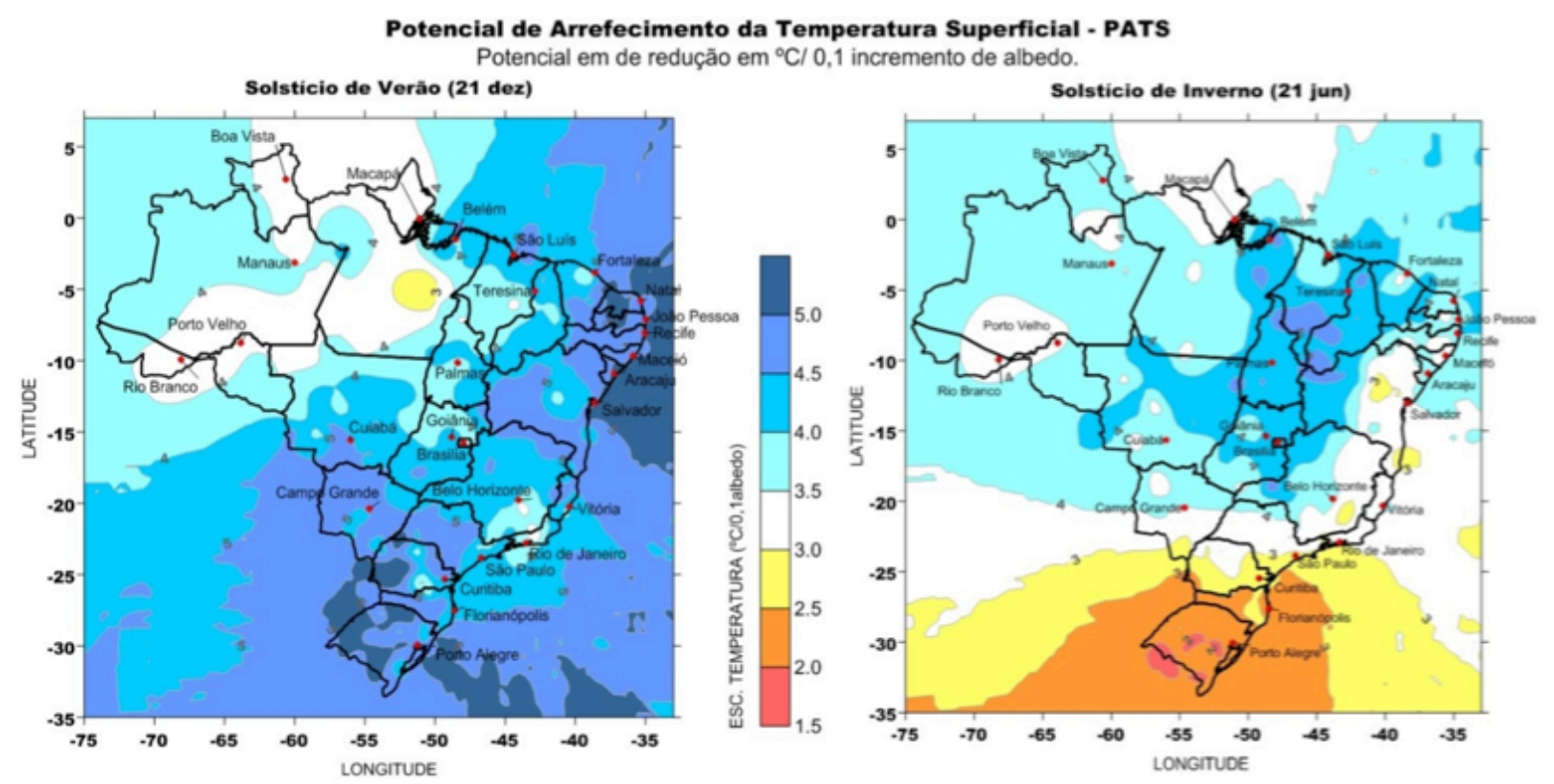

de redução de temperaturas superficiais, pode causar desconforto visual (ofuscamento) e, com o aumento das trocas radiantes com as edificações no entorno, pode haver consequências em termos de consumo mais elevado de energia em climatização artificial nessas edificações. Embora a radiação de onda longa emitida a partir de superfícies pavimentadas urbanas de maior valor de albedo seja menor, com a diminuição do calor sensível próximo à superfície do solo, a parcela refletida será maior. Considerando que as edificações urbanas podem ter grande percentual de seu envelope destinado a áreas envidraçadas, e que o vidro é mais transparente à radiação de onda curta (luz visível) do que à radiação de onda longa (calor), modificações no albedo podem trazer consequências no espaço construído. Sailoret al. (2012) conduziram estudos com o modelo de predição de temperatura em cânions urbanos CAT (CanyonAmbientTemperature, ERELL \& WILLIAMSON, 2006) em combinação com o software EnergyPlus para uma edificação padrão em situações de cânion urbano, com modificações no albedo local 
para cidades de clima quente nos Estados Unidos Houston, Texas (quente úmido) e Phoenix, Arizona (quente seco). Adotaram-se diferentes condições de exposição solar, áreas de envidraçamento (fator WWR - windowtowallratio) e relações H/W (altura média da edificação por largura da via), estimando-se a demanda energética em climatização para situações de inverno e verão. A alteração do albedo local de asfalto para pavimento em concreto trouxe um aumento em termos de carga de refrigeração de $2-5 \%$ para as condições analisadas.

Outro estudo, investigando os efeitos do aumento do albedo local nos graus de conforto no nível do pedestre com o índice de conforto ITS (Index ofThermal Stress), para condições de clima árido, foi realizado por Erellet al. (2012). A partir de dados preditos pelo modelo CAT, para diferentes orientações de via e relações H/W, o estudo calculou resultados em termos de ITS para uma situação de verão (solstício) em Eilat, Israel $\left(29,6^{\circ} \mathrm{N}\right)$, considerando modificações no albedo local de 0,2 (asfalto) para 0,45 (concreto) para 0,7 (cor clara). Os resultados apontaram para uma redução não significativa na temperatura ambiente com o aumento do albedo. A análise do efeito global da modificação do albedo mostrou que, enquanto há uma diminuição na parcela de onda longa irradiada pela superfície, o efeito combinado (radiação de onda curta refletida pela superfície) traz maior estresse térmico ao nível do pedestre. Considerando, entretanto, as limitações desse estudo relatadas pelos autores, em especial, na estimativa da temperatura do ar pelo modelo CAT resultante de alterações no albedo, um aprofundamento da análise acima, com a verificação de alterações do albedo local no microclima urbano ao nível do pedestre, sob as condições subtropicais é plenamente justificável. Acrescentando-se a isso as condições climáticas do sul do Brasil, onde em geral não há uso extensivo de climatização artificial para refrigeração, pode-se indagar sobre o efeito líquido das modificações do albedo local no consumo energético de edificações urbanas.

\section{Conclusões}

A partir dos mapas temáticos apresentados neste trabalho podemos concluir que a adoção de materiais de alto albedo nas superfícies urbanas pode ter um impacto bastante significativo na meIhoria do conforto térmico urbano e na redução dos efeitos de ilha de calor para uma grande extensão do território. Porém, para que seu uso seja benéfico, deve-se considerar seu efeito de redução da temperatura superficial de maneira conjunta com outros possíveis efeitos, como o ofuscamento e o aumento da radiação refletida para o interior das edificações.

Estando a temperatura de superfície diretamente relacionada à intensidade de radiação solar incidente para um mesmo albedo, é útil considerar as variações na distribuição de Irradiância Solar sobre cada região e para cada período do ano, a fim de avaliar corretamente a correlação entre o incremento de albedo e o potencial de arrefecimento da superfície obtido com esse incremento, em diferentes regiões do país.

Nota-se ainda o potencial que o uso correto de albedos mais altos como estratégia passiva de conforto em regiões de altas latitudes com verões quentes e invernos mais rigorosos, uma vez que o efeito de arrefecimento do albedo é variável conforme a intensidade de radiação disponível.

\section{Referências bibliográficas}

AMORIM, M. C. C. T.; DUBREUIL, V.; QUENOL, H. ; SANT'ANA NETO, J. L. Características das ilhas de calor em cidades de porte médio: exemplos de Presidente Prudente (Brasil) e Rennes (França). Confins [Online] - 7, 2009. Posto online em 31 Outubro 2009. Consultado em 29 Julho 2012. Disponível em: http://confins.revues. org/6070 ; DOI : 10.4000/confins.6070

DOULOS, L.; SANTAMOURIS, M.; LIVADA, I. Passive cooling of outdoor urban spaces: The role of materials. Solar Energy, n.77, p. 231-249, 2004.

ERELL, E.; PEARLMUTTER, D.; BONEH, D. Effect of high-albedo materials on pedestrian thermal comfort in urban canyons. In: International Conference on Urban Climates, 8, 2012. Dublin. Anais... Dublin: ICUC, 2012.

ERELL, E.; WILLIAMSON, T. Simulating air temperature in an urban street canyon in all weather conditions using measured data at a reference meteorological station. InternationalJournalofClimatology, n.26, p.1671-1694, 2006.

GARTLAND, L. Ilhas de calor: como mitigar zonas de calor em áreas urbanas. São Paulo: Oficina de Textos, 2010.

KONOPACKI, S.;AKBARI, H.Energy Savings of Heat-Island Reduction Strategies in Chicago and Houston: Including Updates for Baton Rouge, Sacramento, and Salt Lake City. [S.I.]: U.S. Departmentof Energy, 2012. Disponível em: http://www.osti.gov/bridge/purl.cover. 
jsp?purl=/795970-5aGTzF/native/795970.pdf.

Acesso em: 01/03/2013.

LEMOS, J. S. Espacialização da llha de Calor do Aglomerado Urbano da Região Metropolitana de Curitiba (AU-RMC) em agosto de 2006 a partir de termografia de superfície. In: Simpósio Brasileiro de Sensoriamento Remoto - SBSR, XV., 2011. Curitiba. Anais...Curitiba: INPE, 2011. p.4271.

LI, H.; HARVEY, J.; KENDALL, A. Field measurement of albedo for different land cover materials and effects on thermal performance.Building and Environment, v. 59, p. 536-546, Jan 2013. ISSN 0360-1323. Disponívelem: <<Go to ISI>:// WOS:000314371900049 >.

RORIZ, M. Base de dados climáticos de 411 municípios brasileiros. [S.I.]: ANTAC, 2012a. Disponível em: http://www.roriz.eng.br/epw_9. html. Acesso em: 12/04/2013.

RORIZ, M. Sobre os Arquivos EPW: Arquivos Climáticos de Municípios Brasileiros. [S.I.]: ANTAC, 2012b. Disponível em: http://www.roriz. eng.br/epw_9.html. Acessoem: 13/04/2013.

SAILOR, D.; ERELL, E.; KANG, D.; BOTHAM, D. Building Energy Use Implications of Ground Level Albedo Modification. In: International Conference on Urban Climates, 8, 2012. Dublin. Anais... Dublin: ICUC, 2012. 